\title{
Perspective
}

PERSPECTIVE Actualité en histoire de l'art

2| 2013

Brasil

\section{Fabricação e promoção da brasilidade: arte e questões nacionais}

Jorge Coli

\section{(2) OpenEdition \\ 1 Journals}

\section{Edição electrónica}

URL: http://journals.openedition.org/perspective/5541

DOI: 10.4000/perspective.5541

ISSN: 2269-7721

Editora

Institut national d'histoire de l'art

Refêrencia eletrónica

Jorge Coli, «Fabricação e promoção da brasilidade: arte e questões nacionais », Perspective [Online],

2 | 2013, posto online no dia 01 setembro 2014, consultado o 01 outubro 2020. URL : http://

journals.openedition.org/perspective/5541; DOI : https://doi.org/10.4000/perspective.5541

Este documento foi criado de forma automática no dia 1 outubro 2020. 


\section{Fabricação e promoção da brasilidade: arte e questões nacionais}

Jorge Coli

\section{NOTA DO EDITOR}

Cet article existe en traduction française : Fabrique et promotion de la brésilianité : art et enjeux nationaux.

1 Não é difícil constatar que, ao longo de sua história, a cultura artística formada no Brasil sempre recusou a observação. Nas artes plásticas e na literatura, artistas, intelectuais e escritores fecham-se em um mundo imaginário, cegos diante daquilo que os envolve.

2 Apesar de simples e genérica, essa observação inicial revela características fundamentais da produção artística brasileira. Essas particularidades estão vinculadas a crenças ideológicas, principalmente às noções de identidade nacional e de raízes originárias. Trata-se de ficções, de construtos e de fabulações que intervêm de modo definitivo nas percepções e nas expectativas dos comportamentos individuais e coletivos, nas formas de pensar e na concepção de mundo. Para a história das artes, tal situação significou uma inflexão fortemente nacionalista, que substituiu o exame e a análise aprofundada dos objetos considerados.

Portanto, se considerarmos duas categorias de produção artística - uma que constrói a partir do imaginário e outra que se baseia na observação - podemos afirmar que, na cultura brasileira, a primeira é consideravelmente dominante.

O breve episódio de ocupação holandesa no Nordeste brasileiro ocorrido no século XVII ${ }^{1}$, época em que o Brasil era colônia portuguesa (1500-1822), nos fornece um elemento de comparação: as obras de arte executadas no Brasil pelos holandeses baseavam-se em processos de observação imediata e presencial. Essa era uma das características mais 
ricas desses artistas protestantes, modernos, científicos em vários sentidos. Franz Post, por exemplo, mesmo quando pintava o Brasil de memória após seu retorno à Holanda, sempre se fundamentou em um olhar testemunhal. Em 300 anos de colônia portuguesa, a maior parte dos documentos históricos visuais que retratam a vida cotidiana daqueles tempos provém dos oito anos em que Maurício de Nassau governou o Nordeste do país.

É interessante pôr em contraste com essa produção holandesa "realista" o quadro A morte do Padre Philippe Bourel, um dos raros exemplos de pintura colonial que foge dos temas religiosos canônicos (século xvII, Rio de Janeiro, Museu Nacional de Belas Artes). O catálogo museu atribui a obra a um autor desconhecido pertencente à "Escola Portuguesa" do século XVIII e algumas hipóteses a situam por volta de 1730 . A sua decifração iconográfica é fascinante ${ }^{3}$. A localização em uma colina próximo a duas cidades fortificadas (que não encontram equivalente na arquitetura brasileira) e as palmeiras exóticas, que na realidade são tamareiras - espécie não local, mas fortemente carregada de ressonâncias iconográficas (árvore do paraíso e da fuga ao Egito e também metáfora da cruz); o papagaio, ave exótica abundante no Brasil, é fato, mas, antes disso, símbolo da palavra missionária, empregado, por exemplo, pelo Padre Andrea Pozzo no teto da Igreja de Santo Inácio, em Roma, para ilustrar a Alegoria do trabalho missionário dos jesuítas ${ }^{4}$; a cabana, abrigo precário que protege o missionário em sua agonia e cuja fragilidade contrasta com a solidez das cidades ao longe, revela, sobretudo, os fundamentos da cultura erudita e humanista sobre a qual a imagem repousa. Para o pintor, não se trata de modo algum de reproduzir empiricamente uma choupana brasileira e, muito menos, uma oca (que, desde as primeiras ilustrações para as aventuras de Hans Staden no Brasil, era representada de maneira totalmente diferente, com suas coberturas semicilíndricas). $O$ pintor não foi buscar nenhuma referência local. Procedeu por meio do raciocínio humanista e clássico: devo representar uma cabana primitiva; procuro portanto a autoridade que me oferece seu modelo. Essa autoridade é uma só: Vitrúvio. O modelo da cabana procede claramente de ilustrações das edições renascentistas do De Architectura.

6 Essa situação se prolongou no século XIX. A independência do Brasil, em 1822, e a constituição do império brasileiro estimularam a fabricação de um projeto histórico - a construção de uma história para a nova nação - fundamentado tanto em instituições científicas (como o Instituto Histórico e Geográfico Brasileiro, criado em 1838) quanto em formas mais difusas da cultura.

7 Na época do romantismo, surgiu uma corrente artística e literária cujas consequências foram além do âmbito propriamente cultural e interferiram, com força ideológica, nos campos histórico e historiográfico. Trata-se do "indianismo", movimento que celebrava os indígenas brasileiros, atribuindo-lhes nobreza, força heroica e caráter altaneiro ${ }^{5}$. Está claro que esse índio idealizado era puramente imaginário, e sua exaltação cultural correspondia temporalmente ao início da exterminação que se prolongou pelo século $\mathrm{xx}$ afora.

8 Ao tornar-se símbolo, o índio imaginário encarnava o ancestral nobre invocado pelos brasileiros. Ele permitia neutralizar o passado colonial, oferecendo uma origem elevada e autóctone. Essa imagem estava presente até mesmo na simbologia oficial: o manto de coroação do imperador Pedro I era recoberto de penas de tucano, evocando a maneira de enfeitar-se dos indígenas, como se ele tivesse recebido essa insígnia de poder dos ancestrais locais, eliminando os séculos de colonização. Um quadro anônimo, exposto no Museu Padre Toledo da Fundação Rodrigo Mello Franco de Andrade, revela o caráter 
institucional desses processos alegóricos: diante do imperador, ajoelha-se o índio - a personificação o império brasileiro. $O$ caráter autônomo do jovem império reforçava assim a expressão de sua independência em relação à antiga metrópole. Nas caricaturas de jornais do século XIX, o índio, muitas vezes apresentado como Sr. Brasil, encarnou o país, atuando em situações políticas diversas.

9 A celebração do indígena como força suprema e entidade ancestral incidia sobre um outro aspecto, além do já mencionado: ela bloqueava a incorporação do negro pela cultura local. Ao contrário dos índios, que permaneciam em seu habitat natural, os africanos, que chegaram ao Brasil como escravos, eram presença evidente nos universos rural e urbano. Esses escravos eram percebidos como inferiores e como a manifestação quotidiana de um arcaísmo que se tornava cada vez mais insuportável: a escravidão foi abolida apenas em 1888. Graças ao índio, descartava-se o negro do imaginário brasileiro. Salvo exceções, a literatura e as artes plásticas consagraram-se pouco a tomar os negros como tema.

10 Foram sobretudo os artistas estrangeiros, principalmente os franceses, que se interessaram em retratar os tipos e os comportamentos da sociedade brasileira no século XIX. Depois da queda de Napoleão, a corte portuguesa - que havia fugido de Lisboa quando Portugal foi invadido pelo exército de Junot-permaneceu no Rio de Janeiro, então capital do reino de Portugal, prolongando assim o que foi chamado de "inversão metropolitana". A antiga colônia, até então muito fechada aos estrangeiros, abria assim as suas fronteiras. Em 1816, um grupo de artistas franceses chefiados por Joachim Lebreton chegou ao Rio de Janeiro, na chamada Missão Artística Francesa.

11 Dois desses artistas tiveram um papel fundamental no retrato do Brasil daquele período: Nicolas-Antoine Taunay e Jean-Baptiste Debret, ambos formados por JacquesLouis David (que era primo de Debret). Taunay retomou o tema da paisagem, interrompido desde os tempos de Frans Post, e produziu admiráveis vistas do Rio de Janeiro. Debret, com seu Voyage Pittoresque et Historique au Brésil, ou séjour d'un artiste française au Brésil, depuis 1816 jusqu'en en 1831 inclusivement $^{6}$ - obra composta de 153 pranchas litografadas e de um grande número de desenhos e aquarelas, em um espírito propriamente antropológico-retratou um quotidiano carioca sem eufemismos e deixou visualmente documentada a terrível situação dos negros, vítimas de castigos atrozes. Por ironia, os franceses que trouxeram as práticas neoclássicas para o Brasil no século XIX foram percebidos como "inimigos" pelos "modernos" no século Xx: eles os acusavam de terem introduzido uma arte espúria a uma cultura nacional, alegando que o passado artístico com características "verdadeiramente" brasileiras seria o "autêntico" barroco, como se o barroco, ele próprio, não tivesse raízes europeias.

12 Sempre foram os artistas estrangeiros que retrataram o Brasil: os ingleses Edwin Landseer e Chamberlain, o austríaco Thomas Ender, o bávaro Johann Moritz Rugendas, o prussiano Ferdinand Theodor Hildebrandt, entre outros. Todos eles produziram imagens de verdadeira qualidade artística, mas também de grande interesse documental. Sem eles, não haveria registro visual histórico do país, de seus habitantes e de seus comportamentos ao longo de boa parte do século xix. Os artistas brasileiros, ao contrário, dedicavam-se à nobre construção de uma bela história, na qual os índios, sublimes de caráter e de sacrifício, surgiam em imagens grandiosas: Moema, de Victor Meirelles, que ressurge em uma escultura importante de mesmo nome de Rodolpho Bernardelli; Marabá, de Rodolpho Amoedo, e $O$ último Tamoio, do mesmo artista; Iracema, de José Maria de Medeiros (inspirado no romance homônimo de José de Alencar - note- 
se que Iracema é o anagrama de "América"); a grande escultura em terracota Alegoria do Império Brasileiro, de Chaves Pinheiro, para citar alguns exemplos conhecidos ${ }^{7}$. Apenas no final do século, o pintor paulista Almeida Júnior, influenciado por Gustave Courbet, deu atenção ao personagem do caipira interiorano, construindo suas obras a partir do vivido e do observado.

Junto com a exaltação indígena construiu-se outro mito ideológico: o da fusão das três raças. Ao índio, que sem dúvida continuou sendo o grande ancestral protagonista, se juntaram o português e o negro, em uma miscigenação harmoniosa. Esse mito foi reforçado pelo surgimento, em 1936 - momento de forte ideologia nacionalista - , do "homem cordial", criado por Sérgio Buarque de Hollanda, que caracterizou o traço psicológico brasileiro e positivo ${ }^{8}$. Ele foi ainda retomado com muita força recentemente, em 1995, em 0 povo brasileiro, de Darci Ribeiro, que oferece uma versão dramática dessa miscigenação, sem desmistificar, porém, o resultado final, ou seja, a fusão das três matrizes básicas que formam "o brasileiro". Essa síntese matricial exclui, por suposto, todos os "estrangeiros": os imigrantes italianos, japoneses, alemães, coreanos, etc., que chegaram ao Brasil no final do século XIX e remodelaram completamente a geografia humana do país ao longo do século xx.

Algumas obras de arte consagraram-se a instituir essa fusão. Duas delas foram capitais: A primeira missa no Brasil (1860, Rio de Janeiro, Museu Nacional de Belas Artes) e A batalha dos Guararapes (1872-1877, Rio de Janeiro, Museu Nacional de Belas Artes), ambas de Victor Meirelles. A primeira, pintada em Paris e exposta no Salon de 1861, foi inspirada em um documento histórico, a Carta de Pero Vaz de Caminha, na qual o escrivão da frota lusitana comandada por Pedro Álvares Cabral conta ao rei de Portugal a descoberta do Brasil em 1500. Celebrada no século xIX, essa carta, com efeito admirável de narração viva, foi publicada apenas em $1817^{10}$ - ou seja, no momento em que se fazia necessário identificar um documento fundador de uma nova história - e tornou-se "o ato de batismo da Nação", no dizer de um historiador da época. A aceitação desse quadro pelo júri do Salon foi um fato relevante: pela primeira vez um pintor brasileiro, que havia recebido uma bolsa do governo imperial, era reconhecido por uma instituição europeia prestigiosa. Nessa obra, Meirelles procede à interação pacífica entre os recémchegados portugueses e os indígenas locais, em uma cerimônia cristã a céu aberto da qual participa toda a natureza. O segundo quadro, a imensa tela $A$ batalha dos Guararapes $(494,5 \times 923 \mathrm{~cm})$, retrata um combate que uniu portugueses, índios e negros contra o invasor holandês em 1654, batalha definitiva que pôs um termo à ocupação. Essa união, considerada a primeira manifestação de efetiva "brasilidade" pela história nacional, é proclamada em grande espetáculo pela pintura de Victor Meirelles.

No início do século $\mathrm{xx}$, afora conferir uma nova forma às obras e uma irreverência divertida aos discursos, os modernos não mudaram grande coisa nesse panorama: em 1928, o escritor modernista Oswald de Andrade lançou seu "Manifesto Antropofágico" 11 e Mário de Andrade, o romance Macunaíma ${ }^{12}$. Ambos reiteram a celebração indígena e, no caso do romance, a reafirmação do mito matricial das três raças.

Uma obra de exceção que exemplifica as soluções modernistas ao recuperar a presença africana é a tela A negra, de Tarsila do Amaral. Datada de "Paris, 1923", ela foi realizada em pleno apogeu do primitivismo art nègre e ocupa um lugar icônico dentro das artes brasileiras, como expressão autêntica de uma negritude nacional. Está claro, porém, que o caráter emblemático da imagem - forte e admirável - elimina qualquer referência 
a um realismo individual ou social, projetando o personagem em um universo fantástico.

17 Acrescente-se que a presença do negro nas artes não suplantou, ao menos na primeira metade do século, a simbologia indígena. Um caso específico é o de Emiliano Di Cavalcanti. Esse pintor explorou a mitologia erótica das mulatas, objeto de desejo sexual brasileiro emblemático, conferindo a ele um tratamento de aspecto "moderno". Suas célebres mulatas, tão prezadas pelos colecionadores, constituem um caso de "espírito brasileiro" em que a recuperação negra se faz por meio da erotização das mulheres.

18 É bem óbvio que a história da arte não ficou ilesa diante desse nacionalismo. No final do século XIX, Gonzaga Duque ${ }^{13}$, primeira presença verdadeiramente forte da história da arte no Brasil, publicou Arte Brasileira, livro essencial que faz um balanço histórico da produção artística local. Nele, o crítico a condena como convencional, arcaica e ultrapassada: sua postura é moderna. Sem originalidade, repetindo velhas fórmulas, essa arte que nasce velha deve, segundo ele, ser vencida por uma renovação baseada em um princípio de expressões propriamente brasileiras. Insiste em afirmar que o mundo artificial apresentado pelos artistas é incapaz fundar uma escola "autenticamente nacional". Seu desejo é, portanto, o de uma arte que ultrapasse os temas e que encontre, ao mesmo tempo, uma forma moderna e brasileira. Essa obra sem dúvida anunciou as posturas modernistas que surgiram no século Xx.

19 A história cultural brasileira assinala 1922 como o momento em que o modernismo artístico despontou no país. Está claro que houve outras experiências modernas antes disso, mas a Semana de Arte Moderna, ocorrida no Teatro Municipal de São Paulo, tinha condições para chocar uma cidade provinciana que conservava um núcleo intelectual e cultural pouco numeroso - apesar de sua população ter passado de 65.000 habitantes, em 1890, a 580.000, em 1920, graças às imigrações. Mesmo se as obras musicais, literárias e plásticas que foram então apresentadas não eram portadoras de um extremismo vanguardista, eram suficientemente inovadoras para provocar um forte escândalo. No meio desse alvoroço, afirmou-se a personalidade marcante de Mário de Andrade. Teórico fundamental do nacionalismo moderno, ele militava por uma arte autenticamente brasileira que não se baseasse em um exotismo romântico, mas que encontrasse suas raízes profundas e pudesse, assim, ser moderna e atual.

20 Como na época do indianismo romântico, essa preocupação nacionalista era fruto de estímulos internacionais: as demandas de primitivismo bárbaro, degustadas gulosamente na Europa, fazia com que a cultura brasileira produzisse a barbárie que dela se esperava - barbárie essa que foi tomada como essência e incorporada pelos brasileiros como característica própria e natural.

21 Macunaíma, o romance - ou a rapsódia - de Mário de Andrade, cuja ficção combina elementos mitológicos e traços culturais vindos de todas as partes do Brasil, foi publicado em 1928, no mesmo ano em que o seu Ensaio sobre a música brasileira, livro de caráter teórico cujos fundamentos ultrapassam largamente o campo musical para oferecer bases normativas a uma prática geral das artes ${ }^{14}$. Essas duas obras formam, assim, o projeto teórico e o seu exemplo prático. Em ambos, encontra-se a eliminação de todo regionalismo em benefício de uma síntese (a qual Mário de Andrade certamente estava convencido de possuir dentro de si), sem contar, está claro, o efeito próprio a todo nacionalismo, que é o de apagar diferenças de classe em benefício de uma identidade nacional. 
22 A defesa de tais posturas situava-se no momento da afirmação dos poderes totalitários que despontavam na Europa e também na América Latina. Inútil insistir sobre as afinidades entre tais convicções e a ditadura dos anos 1930 de Getúlio Vargas, que sabia arregimentar os nacionalismos de várias procedências e usá-los a serviço do poder autoritário. Depois de um período na Europa durante o qual sua música buscou experimentações mais livres e ousadas, marcadas por certo exotismo, como esperado pelo público europeu - é a época de seus Choros -, Heitor Villa-Lobos (que participara da Semana de Arte Moderna em São Paulo) voltou ao Brasil e tornou-se o grande compositor do regime: criou imensos corais infantis e juvenis nas escolas, compôs obras patrióticas e promoveu um forte retorno à ordem com suas Bachianas, em que mesclou a inspiração do mestre de Leipzig com temas do folclore brasileiro. O próprio Mário de Andrade foi chamado ao Rio de Janeiro para exercer uma função semelhante à de assessor do ministro da Educação, Gustavo Capanema, que se encarregava também das questões culturais. Além dele, Candido Portinari, vinculado à história do Partido Comunista, foi convidado para decorar, entre 1944 e 1947, o palácio do Ministério da Educação e Saúde, cuja arquitetura foi inspirada em um projeto de Le Corbusier e realizada por Lucio Costa, chefe de uma equipe de arquitetos que contava também com Oscar Niemeyer. Escultores da importância de Bruno Giorgi e Jacques Lipschitz, assim como o paisagista Roberto Burle Marx, se associaram nessa empreitada que afirmava o caráter oficial dos modernistas.

23 As posições teóricas e nacionalistas de Mário de Andrade pressupunham dois inimigos principais. Um deles era o prestígio da cultura internacional, particularmente das culturas europeia e francesa, esta última de grande presença no Brasil. Era preciso proteger-se de influências indesejáveis que traíssem aquilo que considerava ser uma "essência" nacional. O segundo, mais delicado e de inflexões sociais mais complexas, era a chegada de centenas de milhares de imigrantes italianos, japoneses, alemães, sírio-libaneses, entre outras origens, que privilegiavam a cidade ou o estado de São Paulo como escolha principal, atingindo exatamente o universo geográfico de Mário de Andrade e dos modernos de 1922. O mito orgânico da fusão das três raças servia para excluir a cultura não brasileira trazida por esses imigrantes e para exigir deles uma integração nesse ideário nacional, o que significava o sacrifício de seus aportes próprios.

24 Os princípios teóricos e ideológicos baseados nos fundamentos dessa "cultura brasileira" alicerçada no século xIX foram assim retomados pelo movimento modernista no século xx. Essa construção, totalmente ideológica, foi - e ainda é em grande parte vivida coletivamente de maneira orgânica, ontogenética. $O$ mito das três raças serviu para excluir a cultura dos imigrantes, que tinham, além de tudo, um handicap: eram trabalhadores braçais ou pequenos comerciantes, ao contrário da elite local, que se vangloriava de suas origens luso-indígenas (nunca negras) com fumos de aristocracia e que se mostrou incentivadora dos modernos. Era também um modo persistente e repetitivo de reiterar uma estratégia sentimental coletiva.

25 Nesse espírito, Mario de Andrade inventou uma história das artes teleológica, promovendo uma engenhosa revisão do passado. Ela já aparece constituída em seu Ensaio sobre a música brasileira, no qual ele diz querer consolidar um "espírito de raça" e imagina, grosso modo, três fases históricas para a criação artística no Brasil, começando pelo período que poderíamos chamar de "inconsciente". Os criadores, ao longo da história, se deixaram penetrar por um espírito brasileiro sem darem por isso. 
Como corolário, o estudioso deve tratar de identificar, por exemplo, no padre José Maurício, importante compositor da corte portuguesa no Rio de Janeiro, os traços de brasilidade. Este é o papel essencial do historiador da arte: detectar as características brasileiras. Depois, vem o momento "voluntarioso", para empregar a palavra de Mário de Andrade, em que ele próprio e seus contemporâneos se encontram. É preciso "querer ser" brasileiro, disciplinar-se, servindo-se dos exemplos locais, preferencialmente buscados em uma perspectiva antropológica. Enfim, Mário de Andrade prevê um futuro plenamente nacional: "ela [a música e, implicitamente, todas as artes] terá que se elevar ainda à fase que chamarei de Cultural, livremente estética, e sempre se entendendo que não poderá haver cultura que não reflita as realidades profundas da terra em que se realiza. E então a nossa música será, não mais nacionalista, mas simplesmente nacional, no sentido em que são nacionais um gigante como Monteverdi e um molusco como Leoncavallo"15. Os artistas contemporâneos deveriam, portanto, fazer um esforço para serem "nacionais", antes de se tornarem "naturalmente" nacionais.

A história das artes proposta por Mário de Andrade pretendia buscar indícios nacionais nas obras do passado. Tratava-se, portanto, de descobrir os precursores, artistas que, no mais das vezes contra suas próprias intenções de obedecerem aos modelos europeus, incorporaram traços brasileiros em suas características e maneiras; ou seja, agentes inconscientes de brasilidade contra as grandes referências internacionais. Mário de Andrade traçara um vetor no tempo: quanto mais antigos eram os artistas, mais as marcas de brasilidade eram fracas. À medida em que, progressivamente, uma cultura brasileira se afirmava, esses traços também se evidenciavam mais e mais. Não importava a qualidade das obras. Mário de Andrade reiteradamente repetiu sua desconfiança diante do "gênio": uma personalidade criadora excepcional, com seus particularismos, compromete o desenvolvimento coletivo "médio" da criação artística. Essa "média" torna-se o ponto principal da questão: as obras de fato significativas que a história da arte e da cultura brasileiras deveria levar em conta não eram as mais inovadoras, nem as mais elaboradas, nem as mais inventivas e excepcionais. $O$ que contava para essa história da arte era o grau de brasilidade, maior ou menor, mais tardio ou mais precoce. Quanto mais escapassem aos modelos internacionais, melhores elas eram.

Esses processos simplificadores eram baseados em premissas fortemente ideológicas, já que se tratava de definir o que era ou não era "brasileiro", o fundamento axiomático mais profundo das distinções nacionais.

Essas formulações teóricas tiveram como consequência a valorização das deficiências técnicas, do caráter rudimentar e da falta de habilidade dos artistas brasileiros nas práticas de seus ofícios. Defeitos ou erros que, comparados à maestria hábil estrangeira, podiam revelar uma carência em relação às práticas europeias, mas se definiam, em verdade, como soluções locais que manifestavam uma "alma" artística brasileira, pontos de resistência diante do domínio técnico presente nos centros internacionais. $O$ gosto difuso na época - internacionalmente, se entende - por um primitivismo genérico naturalmente deu apoio a essas convicções.

o folclore foi um dos melhores instrumentos para a caracterização nacional. Serviu para a inspiração artística e foi objeto de pesquisa, a começar pelo polimorfo Mário de Andrade, que foi também etnólogo, antropólogo e folclorista. A modernidade brasileira 
não foi certamente a única a se voltar para o primitivismo e para o arcaísmo, mas é preciso sublinhar a extrema importância dessas noções para esse movimento.

o evolucionismo de Mário de Andrade acompanhava-se também de uma paradoxal negação da história, substituída pelo que poderia ser chamado de uma antropologia atemporal. Isso se manifesta também no pensamento de Lucio Costa, arquiteto e urbanista que se lançou na história da arquitetura brasileira ao publicar muito cedo, em 1929, O Aleijadinho e a Arquitetura Tradicional ${ }^{16}$, mais tarde, em 1937, Documentação necessária ${ }^{17}$, e, enfim, em 1952, Considerações sobre a arte contemporânea ${ }^{18}$, três obras que marcaram e ainda marcam as práticas interpretativas. Esses textos se afinam com as visões de Mário de Andrade. 0 gênio de Aleijadinho não compartilha "com o espírito geral de nossa arquitetura", diz Lucio Costa. Para ele, o centro de referência para a brasilidade é a arquitetura vernácula, doméstica: a casa colonial. Marcelo Puppi fez uma admirável análise em seu Por uma história não moderna da arquitetura brasileira, concluindo a esse respeito que Lucio Costa "pretende instaurar uma antropologia da arquitetura; esta não por acaso torna desnecessário o conhecimento efetivo da própria história disciplinar: a 'história' antropológica elimina a história 'histórica'. A procura do tradicional - vale dizer, o retorno às raízes culturais da nação - equivale à busca de nossa arquitetura primitiva" ${ }^{19}$. Dessa forma, o passado colonial, que age contra as modas estrangeiras e deletérias do século XIX, deve inspirar os arquitetos do presente.

Há claras incidências dessas posturas sobre a preservação do patrimônio, incluindo a maquiagem das assim chamadas cidades históricas de Minas Gerais, como Tiradentes e Ouro Preto, cujas regras de proteção eliminaram os aportes dos séculos xIX e xx e impuseram às novas construções o estilo do século XviII.

No que concerne os estudos sobre o barroco brasileiro, a consequência mais forte é o fechamento sobre si, buscando processos genéticos e evolutivos internos e recusando as práticas comparativas internacionais. Quando Germain Bazin vem ao Brasil em 1945, no élan da política cultural do ministro Gustavo Capanema, para desenvolver seus trabalhos sobre arte e arquitetura barroca, ele se alinha às normas nacionalistas. Isso também ocorre bem mais tarde no livro de Yves Bruand Arquitetura contemporânea no $B$ asil $^{20}$, primeira obra sistemática sobre o assunto, mas que também adere às teses nacionalistas existentes. Independentemente dos indiscutíveis méritos desses autores franceses, seus horizontes são sempre aqueles estabelecidos pelo campo ideológico local.

Esse campo sofreu, no entanto, um estremecimento nos anos 1950, momento de desenvolvimento industrial e de prosperidade econômica que criou uma forte abertura internacional. Assim, foram criados o Museu de Arte de São Paulo, com uma coleção de obras-primas universais compradas em poucos anos, e a Bienal Internacional de São Paulo, que articulava o Brasil com a produção artística mundial. Acontecimentos importantes, mas insuficientes para se imporem ideologicamente e que sofreram o revés do golpe militar de 1964, quando o projeto nacionalista foi fortemente retomado.

Por diversas razões, a história da arte no Brasil se afirmou como disciplina universitária sólida e autônoma somente muito tarde, nos anos 1990. Foram criados, então, vários programas de pós-graduação e, nos últimos anos, algumas graduações específicas. Antes disso, os estudos eram feitos por eruditos de formações as mais diversas, que deixaram obras preciosas, mas que não se articulavam de maneira sistemática e crítica, como era necessário. 
essa mudança fundamental, jovens historiadores formados no rigor das disciplinas acadêmicas voltaram-se para um trabalho sem preconceitos nacionalistas e atualizado internacionalmente. Muitos deles dedicaram-se ao estudo de obras estrangeiras, sobretudo daquelas pertencentes a coleções brasileiras, mas não apenas. Outros se interessaram por obras suscitadas pela presença cultural dos imigrantes e que até então não despertavam interesse - um caso exemplar é o da escultura monumental italiana no século xx. Nos últimos anos, a arte brasileira, acima de tudo, tem sidoposta em perspectiva internacional, seja pelo estudo comparativo, seja pelo trabalho arquivístico executado no exterior ligado aos artistas brasileiros viajantes. Seria impossível enumerar a variedade desses estudos recentes que trouxeram um novo alento e novas compreensões para a história da arte no Brasil.

\section{NOTAS}

1. Após tomarem a cidade de Salvador da Bahia em 1624 e a ocuparem por um ano, os holandeses apossaram-se de Pernambuco, controlando o Nordeste quase que por 24 anos. Entre 1637, quando chegou a Pernambuco, e 1644, quando retornou à Europa, o conde Maurício de Nassau ocupou o cargo de Governador dos domínios conquistados e a conquistar pela Companhia Holandesa das Índias Ocidentais no Brasil. Excelente administrador, ele era também um humanista interessado em desenvolver um projeto científico e artístico no Brasil. Trouxe consigo eruditos e artistas e criou um museu de história natural, um jardim botânico, um zoológico e um observatório astronômico.

2. Alcídio Mafra Souza E., O Museu Nacional de Belas Artes, São Paulo, 1985, p. 238.

3. Cf. Jorge Coli, "Episódio e alegoria", in Anuário do Museu Nacional de Belas Artes, v. 1, 2009, p. 105-128.

4. Cf. Erwin Panofsky, Problems in Titian: Mostly Iconographic, New York, 1969, p. 28-29.

5. Os nomes mais importantes na literatura, entre outros, são, na prosa, José de Alencar, com os romances O Guarani (1857), Iracema (1865) e Ubirajara (1874); na poesia épica, Gonçalves Dias, com I-Juca-Pirama (1851) e Os Timbiras (1856), e Gonçalves de Magalhães, com A confederação dos Tamoios (1856). Na pintura, de manifestação um pouco mais tardia, os principais nomes são Victor Meirelles, Rodolfo Amoedo e Antônio Parreiras. Um lugar relevante deve ser reservado ao compositor Antonio Carlos Gomes, que apresentou em 1870, no Teatro alla Scala de Milão, a ópera Il Guarany, baseada no romance de Alencar, e criou Lo Schiavo, que estreou no Rio de Janeiro em 1889.

6. Jean-Baptiste Debret, Voyage pittoresque et historique au Brésil, ou Séjour d'un artiste français au Brésil, depuis 1816 jusqu'en 1831 inclusivement, Paris, 1834.

7. Victor Meirelles, Moema (1866, São Paulo, Museu de Arte de São Paulo), inspirado no poema épico Caramuru, de Santa Rita Durão (1781); Rodolpho Bernardelli, Moema (1895, Pinacoteca do Estado de São Paulo); Rodolpho Amoedo, Marabá (1882, Rio de Janeiro, Museu Nacional de Belas Artes), inspirado no poema homônimo de Gonçalves Dias (1851); Rodolpho Amoedo, O último Tamoio (1883, Rio de Janeiro, Museu Nacional de Belas Artes), inspirado no poema épico de Gonçalves de Magalhães A confederação dos Tamoios (1856); José Maria de Medeiros, Iracema (1884, Rio de Janeiro, Museu Nacional de Belas Artes), inspirado no romance homônimo de José de 
Alencar (1865); Chaves Pinheiro, Alegoria do Império Brasileiro (1871, Rio de Janeiro, Museu Nacional de Belas Artes).

8. Sérgio Buarque de Holanda, Raízes do Brasil, São Paulo, 1936.

9. Darcy Ribeiro, O povo brasileiro: a formação e o sentido do Brasil, São Paulo, 1995.

10. A Carta de Pero Vaz de Caminha foi publicada no livro Corografia Brasílica, de Manuel Aires de Casal (Rio de Janeiro, 1817).

11. Oswald de Andrade (1890-1954), poeta, romancista, ensaísta e polemista, foi um dos percursores do movimento modernista e um dos criadores e participantes da Semana de Arte Moderna de 1922, em São Paulo. Seu "Manifesto Antropofágico", publicado em maio de 1928 na primeira edição da Revista de Antropofagia, criada por ele, defendia a ideia de que o canibalismo cultural, naturalmente inspirado de práticas indígenas - absorção de todas as formas de cultura internacional para, com a digestão, transformá-las em cultura brasileira - era a maneira de afirmar uma cultura nacional contra a Europa.

12. Mário de Andrade (1893-1945), poeta, romancista, musicólogo, professor no conservatório de São Paulo, crítico e historiador da arte, e principal teórico do movimento modernista, também teve um papel fundamental na realização da Semana de Arte Moderna de 1922. Seu prestígio como erudito era imenso, e suas intervenções entre os artistas brasileiros de todos os campos foram definitivas. Macunaíma (São Paulo, 1928) é um romance-que o autor chama de "rapsódia" - em que, por meio de situações irreais, baseadas em grande parte na mitologia indígena, ele pretende fornecer uma síntese do que poderia ser chamado de "brasilidade".

13. Luiz Gonzaga Duque Estrada exerceu a crítica de arte no Rio de Janeiro; publicou A arte brasileira: pintura e esculptura (Rio de Janeiro, 1888) e, entre outros textos consagrados à arte, o romance à clef Mocidade morta, (Rio de Janeiro, 1899), em que faz um retrato do meio artístico carioca do final do século XIX.

14. Andrade, 1928, citação n ${ }^{\circ} 12$; Mário de Andrade, Ensaio sobre música brasileira, São Paulo, (1928) 1962.

15. Andrade, [1928] 1962, citação $\mathrm{n}^{\circ} 15$, p. 33-34. Esse esquema foi retomado, com uma perspectiva histórica mais fortemente acentuada, em 1941, no estudo "Evolução Social da Música no Brasil", editado posteriormente no volume Aspectos da música brasileira das obras completas de Mário de Andrade (São Paulo, 1965).

16. Lúcio Costa, "O Aleijadinho e a arquitetura tradicional", in Sobre arquitetura, Porto Alegre, 1966, p. 12-16 [ed. orig. in O Jornal, 1929].

17. Lúcio Costa, "Documentação necessária”, in Costa, 1966, citação nº 17, p. 202-229 [ed. orig. in Revista do SPHAN, 1, 1937].

18. Costa, 1966, citação $\mathrm{n}^{\circ}$ 16, p. 202-229 [ed. orig.: Considerações sobre a arte contemporânea, Rio de Janeiro, 1952].

19. Marcelo Puppi, Por uma história não moderna da arquitetura brasileira, Campinas, 1998.

20. Yves Bruand, Arquitetura contemporânea no Brasil, Campinas, 1981. 